\title{
Methylphenidate enhances extinction of contextual fear
}

\author{
Antony D. Abraham, ${ }^{1}$ Christopher L. Cunningham, and K. Matthew Lattal \\ Department of Behavioral Neuroscience, Oregon Health \& Science University, Portland, Oregon 97239, USA
}

\begin{abstract}
Methylphenidate (MPH, Ritalin) is a norepinephrine and dopamine transporter blocker that is widely used in humans for treatment of attention deficit disorder and narcolepsy. Although there is some evidence that targeted microinjections of MPH may enhance fear acquisition, little is known about the effect of MPH on fear extinction. Here, we show that $\mathrm{MPH}$, administered before or immediately following extinction of contextual fear, will enhance extinction retention in C57BL/6 mice. Animals that received MPH $(2.5-10 \mathrm{mg} / \mathrm{kg})$ before an extinction session showed decreased freezing response during extinction, and the effect of the $10 \mathrm{mg} / \mathrm{kg}$ dose on freezing persisted to the next day. When MPH (2.5$40 \mathrm{mg} / \mathrm{kg}$ ) was administered immediately following an extinction session, mice that received MPH showed dose-dependent decreases in freezing during subsequent tests. MPH administered immediately after a 3-min extinction session or $4 \mathrm{~h}$ following the first extinction session did not cause significant differences in freezing. Together, these findings demonstrate that MPH can enhance extinction of fear and that this effect is sensitive to dose, time of injection, and duration of the extinction session. Because MPH is widely used in clinical treatments, these experiments suggest that the drug could be used in combination with behavioral therapies for patients with fear disorders.
\end{abstract}

[Supplemental material is available for this article.]

Following the experience of an unconditioned stimulus (US) such as footshock in a certain context (conditioned stimulus, CS), an animal will associate those contextual cues with the US. If reexposed to those cues without the shock, the fearful reaction evoked by those cues will be suppressed. This suppression occurs through an extinction process that is a form of behavioral and neural adaptation that allows an organism to modify responding in the presence of conditioned cues (Myers and Davis 2007).

At the clinical level, extinction learning is an important aspect of treatment in therapies for a variety of diseases including drug addiction, phobias, and fear disorders such as post-traumatic stress disorder (PTSD) (Quirk and Mueller 2008). Behavioral treatments for these disorders often include exposure therapy, in which a patient is exposed to a fear-arousing stimulus in the absence of an aversive stimulus in order to reduce fear response. Pharmacological methods for enhancing extinction are of value for clinicians to increase exposure therapy efficacy. In particular, drugs that enhance prefrontal cortical activity are of interest due to demonstrations of a correlation between decreased activation of the medial prefrontal cortex (mPFC) with increased PTSD symptom severity (Shin et al. 2006) and to demonstrations of a role of the mPFC in inhibiting learned fear responses (VidalGonzalez et al. 2006). Thus, developing pharmacological approaches that target prefrontal function may be useful for treatments that are designed to promote extinction (Quirk et al. 2006).

Several experiments have shown that psychostimulants can alter prefrontal cortex function. For example, acute cocaine or amphetamine administration increases extracellular availability of dopamine in the mPFC (Sorg and Kalivas 1993; Mazei et al. 2002). Although there is some evidence for fear extinction enhancements with intra-mPFC infusions of amphetamine (Pezze et al. 2003), the literature is generally mixed, with no effect

'Corresponding author.

E-mail abrahaan@ohsu.edu.

Article is online at http://www.learnmem.org/cgi/doi/10.1101/lm.024752.111.
(Mueller et al. 2009; Carmack et al. 2010) or even extinctionimpairing effects of systemic administration of amphetamine or cocaine (Miczek and Luttinger 1978; Borowski and Kokkinidis 1998). These studies have examined psychostimulant effects on extinction following pre-session injections, which result in large locomotor effects that may interfere with the animal's ability to retrieve or express fear memory.

Methylphenidate hydrochloride (MPH) is a dopamine (DA) and norepinephrine (NE) transporter blocker that has been approved for use in attention deficit hyperactivity disorder (ADHD) and narcolepsy under the trade name Ritalin. Deficits in prefrontocortical functioning are thought to underlie ADHD and may be related to decreased catecholamine terminals in the prefrontal cortex of ADHD adults (Arnsten and Dudley 2005). Berridge et al. (2006) demonstrated that low doses of MPH $(0.25-2.0 \mathrm{mg} / \mathrm{kg})$ preferentially increased DA and NE extracellular levels in the prefrontal cortex and improved spatial working memory in the delayed alternation task in Sprague-Dawley rats. Zheng et al. (2008) found that a single post-training session infusion of MPH into the anterior cingulate or the basolateral amygdala augmented fear memory consolidation in a step through inhibitory avoidance task but did not see effects of systemically injected $\mathrm{MPH}(0.5 \mathrm{mg} / \mathrm{kg}$ and $5 \mathrm{mg} / \mathrm{kg})$. Recently, acute administration of MPH in rats has been shown to facilitate cortico-amygdalar plasticity following a cue-reward learning task (Tye et al. 2010). Because the prefrontal cortex is important for fear extinction (Myers and Davis 2007), there is a strong likelihood that MPH may enhance the development and persistence of extinction through preferential activation of dopamine and norepinephrine receptors in the prefrontal cortex.

The following experiments examine the effects of acute systemic MPH administration in contextual fear extinction before, immediately after, or $4 \mathrm{~h}$ after a single longer (12-min) extinction session or following a relatively shorter (3-min) extinction session. The persistence of MPH effects was tested for $3 \mathrm{~d}$ after the first extinction session. The use of pre- and post-session injections 


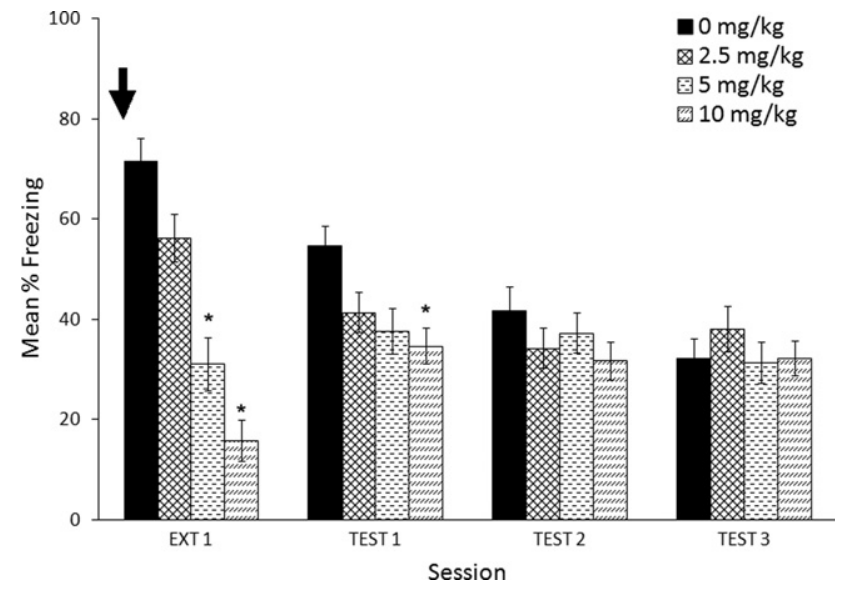

Figure 1. Effects of MPH (black arrow) administered immediately before a 12-min extinction session. Mice that received methylphenidate showed differences in freezing response during the Extinction session (5 and $10 \mathrm{mg} / \mathrm{kg}$ ) and during Test Day $1(10 \mathrm{mg} / \mathrm{kg})$. Error bars indicate SEM. $\left({ }^{*}\right) P<0.05$ significant difference compared with saline (Dunnett's test).

allows us to specifically examine effects of MPH on acquisition and consolidation of the learning that occurs during extinction.

\section{Results}

Experiment 1: Pre-extinction session administration of $\mathrm{MPH}$ reduces freezing during extinction and testing This experiment examined the effect of MPH $(0,2.5,5$, or $10 \mathrm{mg} /$ $\mathrm{kg}$ ) on extinction acquisition through the use of a single pre-session administration immediately before extinction.

Figure 1 shows that pre-session administration of MPH caused a dose-dependent reduction in freezing during the extinction session (Ext 1 in Fig. 1). A one-way between-subjects ANOVA found significant effects of MPH on freezing $\left(F_{(3,28)}=12.7, P<0.0005\right)$. Post hoc comparisons with a Dunnett's test showed that saline was significantly different from $5 \mathrm{mg} / \mathrm{kg}(P=0.001)$ and $10 \mathrm{mg} /$ $\mathrm{kg}(P<0.0005)$ but not from $2.5 \mathrm{mg} / \mathrm{kg}(P=0.305)$. This effect was likely due to the locomotor effects of $\mathrm{MPH}$, because doses of 10 and $20 \mathrm{mg} / \mathrm{kg} \mathrm{MPH} \mathrm{showed} \mathrm{significant} \mathrm{differences} \mathrm{in} \mathrm{locomotor}$ activity compared with saline (Supplemental Fig. 1).

Test day analyses indicated that the effects of MPH persisted to the first drug-free test, when methylphenidate-treated $(10 \mathrm{mg} / \mathrm{kg})$ animals froze less than saline-treated animals (Test 1 in Fig. 1). This effect did not persist to Tests 2 and 3 . These effects were confirmed by a Dose $\times$ Test Day ANOVA that found no main effect of Dose $\left(F_{(3,28)}=0.6, P=0.633\right)$ but did find a significant main effect of Test Day $\left(F_{(2,56)}=7.5, P=0.001\right)$, as well as a reliable interaction for Dose $\times$ Test Day $\left(F_{(5,43)}=2.5, P=0.049\right)$. Post hoc analyses of individual test days did not show significant effects for doses, but there was a trend $\left(F_{(3,28)}=2.4, P=0.085\right)$ on Test Day 1 that was not seen on other test days. A Dunnett's test confirmed that there was a significant effect of MPH at $10 \mathrm{mg} / \mathrm{kg}$ compared with saline on Test Day $1(P=0.048)$ when administered before an extinction session.

\section{Experiment 2: Post-extinction session administration of} $\mathrm{MPH}$ dose-dependently enhances retention of extinction Experiment 2 tested the effects of MPH (0, 2.5, 5, 10, 20, or $40 \mathrm{mg}$ / $\mathrm{kg}$ ) on extinction consolidation using a single post-session administration of MPH immediately following Extinction.
Figure 2 indicates that there was a persistent effect of methylphenidate administration that caused lower freezing across test days. Animals that received $20 \mathrm{mg} / \mathrm{kg}$ MPH showed reliably lower freezing compared with the saline group, while animals that received other MPH doses did not show reliable differences across test days. Statistical analysis confirmed a significant main effect of Dose $\left(F_{(5,82)}=3.5, P=0.006\right)$ and Test Day $\left(F_{(2,130)}=17.0, P<\right.$ $0.0005)$. There was no significant Dose $\times$ Test Day interaction $\left(F_{(8,130)}=0.607, P<0.770\right)$. Post hoc analysis with Dunnett's test showed an overall significant difference between saline and $20 \mathrm{mg} / \mathrm{kg}(P=0.007)$.

To examine the test effects more closely, we analyzed withinsession differences between each dose of MPH and saline during each test session. Figure 3 shows the results of each test session plotted in 3-min time blocks. There were no differences across tests between saline and the $2.5 \mathrm{mg} / \mathrm{kg}$ dose (Fig. 3A). Post-extinction administration of $5 \mathrm{mg} / \mathrm{kg}$ MPH (Fig. 3B) caused a transient difference in freezing during the first $3 \mathrm{~min}$ of Test $1\left(t_{(32)}=2.7\right.$, $P=0.012)$. Post-extinction administration of $10 \mathrm{mg} / \mathrm{kg} \mathrm{MPH}$ (Fig. 3C) caused decreased freezing in Blocks 1 and 2 of Test 1 compared with saline $\left(t_{(42)}=2.8, P=0.008\right.$, and $t_{(42)}=2.0, P=0.049$, respectively), as well as an overall effect of $10 \mathrm{mg} / \mathrm{kg} \mathrm{MPH} \mathrm{for} \mathrm{Test}$ $1 \quad\left(t_{(42)}=2.2, \quad P=0.036\right)$. Post-extinction administration of $20 \mathrm{mg} / \mathrm{kg}$ MPH (Fig. 3D) caused decreased freezing during Test 1 $\left(t_{(44)}=2.6, P=0.012\right)$, Test $2\left(t_{(44)}=3.3, P=0.002\right)$, and Test 3 $\left(t_{(44)}=3.1, P=0.004\right)$. Post-extinction administration of $40 \mathrm{mg} /$ $\mathrm{kg} \mathrm{MPH} \mathrm{(Fig.} \mathrm{3E)} \mathrm{trended} \mathrm{toward} \mathrm{decreased} \mathrm{freezing} \mathrm{compared}$ with saline during Test $1\left(t_{(32)}=2.0, P=0.051\right)$, with the second and third blocks showing significant differences $\left(t_{(32)}=2.7, P=\right.$ 0.011 , and $t_{(32)}=2.4, P=0.02$, respectively). The $40 \mathrm{mg} / \mathrm{kg}$ $\mathrm{MPH}$ dose (Fig. 3E) was significantly different from saline during Test $3\left(t_{(32)}=2.237, P=0.032\right)$, with reliable differences during the second block $\left(t_{(32)}=3.8, P=0.001\right)$.

To assess potential nonspecific effects of these doses on locomotion, we conducted another experiment that was identical to Experiment 2, except that there was no shock in Day 1 (i.e., postsession injections following Day 2 and subsequent testing on Days $3-5)$. We found no effects of these doses on locomotor behavior during any of the sessions (Supplemental Fig. 2). Thus, although there are clear acute locomotor effects of MPH (Supplemental Fig. 1), these effects do not persist to further test sessions, indicating that the effects on freezing in Figures 2 and 3 are likely not due to simple persistent effects on activity.

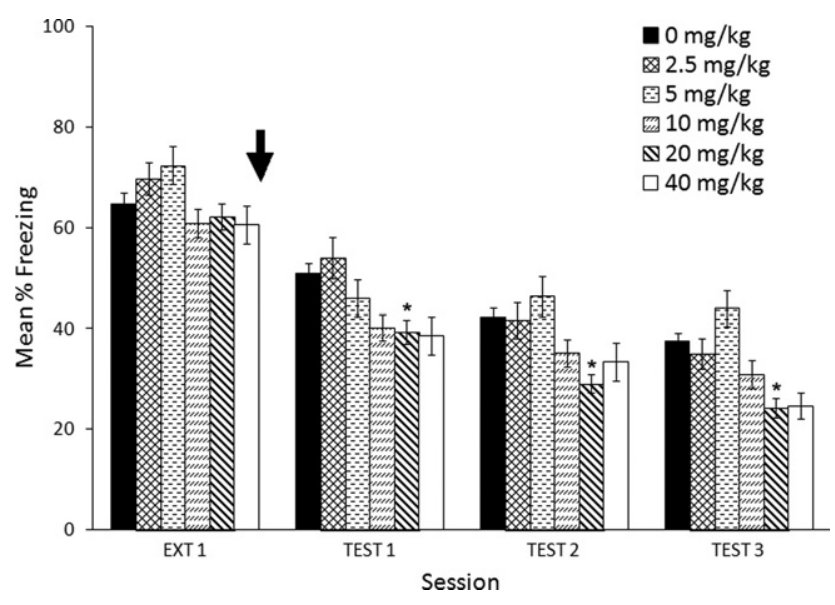

Figure 2. Between-session effects of MPH (black arrow) administered immediately after a 12-min extinction session. Error bars indicate SEM. $\left(^{*}\right) P<0.05$ significant difference compared with saline. 

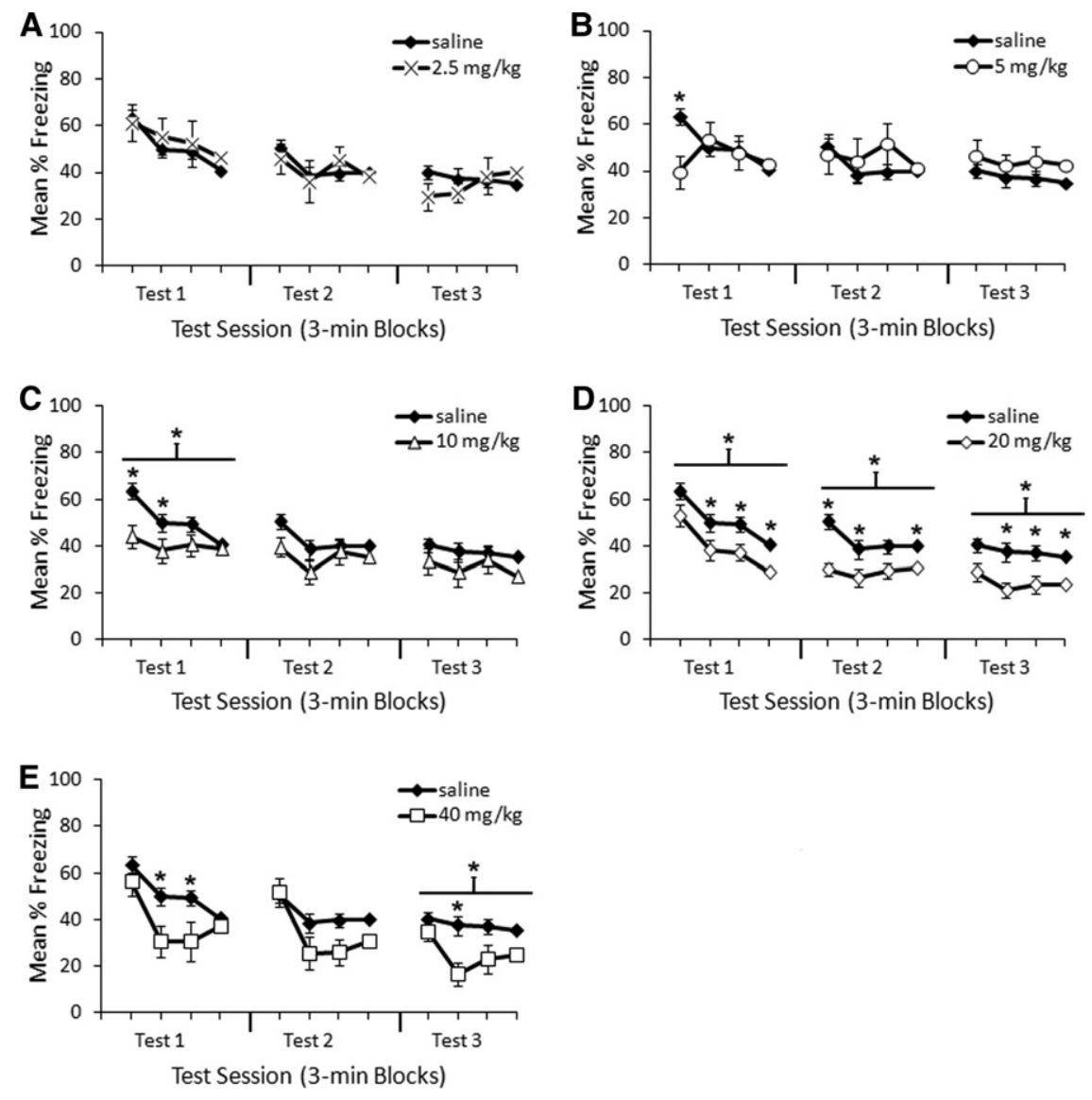

Figure 3. Within-session effects of MPH administered immediately after a 12-min extinction session. Comparisons of methylphenidate doses $(2.5,5,10,20$, and $40 \mathrm{mg} / \mathrm{kg}$, panels $A-E$, respectively) to saline during test sessions revealed differences during particular 3-min blocks for all doses higher than $2.5 \mathrm{mg} / \mathrm{kg}$. Error bars indicate SEM. $\left(^{*}\right) P<0.05$ significant difference compared with saline. (Asterisk [*] above black line) Significant difference compared with saline over total test session.

\section{Experiment 3: Four-hour delayed administration of $\mathrm{MPH}$ following an extinction session has no effect on retention of extinction}

To test whether the extinction enhancement effects seen in Experiments 1 and 2 were due to the temporal proximity of the injection to the extinction session, animals were administered a single dose of MPH $4 \mathrm{~h}$ following an extinction session. If $\mathrm{MPH}$ targets extinction memory consolidation, then a 4 -h post-session injection should have little effect. Animals were returned to their homecage during the 4 -h interval before being administered methylphenidate $(0,20$, or $40 \mathrm{mg} / \mathrm{kg})$.

Although Figure 4 visually suggests a dose-dependent effect of $\mathrm{MPH}$ on extinction, there was no significant effect of MPH treatment on freezing during test days. Statistical analysis confirmed that there was no main effect of Dose $\left(F_{(2,29)}=0.7, P=\right.$ $0.503)$ but there was a significant effect of Test Day $\left(F_{(2,58)}=\right.$ 23.4, $P<0.0005)$. There was no Dose $\times$ Test Day interaction $\left(F_{(4,58)}=1.341, P=0.266\right)$. Within-session analysis of test days confirmed that there were no test days or 3-min blocks significantly different from saline at $20 \mathrm{mg} / \mathrm{kg}$ or $40 \mathrm{mg} / \mathrm{kg} \mathrm{MPH}$.

\section{Experiment 4: Brief extinction immediately followed by} administration of MPH has no effect on extinction retention This experiment examined the effects of MPH $(0,10,20 \mathrm{mg} /$ $\mathrm{kg}$ ) on extinction under conditions of reduced within-session extinction. Figure 5 shows no effect of MPH on freezing during test days. Statistical analysis confirmed that there was no main effect of Dose $\left(F_{(2,21)}=\right.$ $0.416, P=0.665)$, but there was a significant effect of test days $\left(F_{(2,42)}=20.7, P<\right.$ $0.0005)$ and no Dose $\times$ Test Day interaction $\left(F_{(4,42)}=0.924, P=0.459\right)$.

\section{Discussion}

These experiments demonstrate that extinction can be enhanced by MPH under certain conditions. Pre-session injections of MPH (10 mg/kg) promoted extinction on Test Day 1, but this effect was complicated by locomotor activation during extinction (Experiment 1). Experiment 2 showed that a single post-extinction session administration of MPH caused extinction enhancement on subsequent test days. This effect was most obvious with the $20 \mathrm{mg} / \mathrm{kg} \mathrm{MPH}$ dose but other doses $(5,10$, and $40 \mathrm{mg} / \mathrm{kg})$ also revealed enhancements. The extinction enhancements were not observed when MPH was administered $4 \mathrm{~h}$ following extinction (Experiment 3). No extinction or fear memory enhancement occurred when the animal received a brief extinction trial followed by MPH administration (Experiment 4). These results are consistent with literature demonstrating the importance of dopaminergic and noradrenergic signaling for extinction learning (Bernardi and Lattal 2010; Holtzmann-Assif et al. 2010).

Previous studies that have examined DAT and NET blockers such as cocaine or amphetamine have generally used a presession administration paradigm to determine whether these drugs may have effects on fear acquisition or extinction (e.g., Pezze and Feldon 2004). One challenge in interpreting results of experiments with pre-session injections is disentangling the

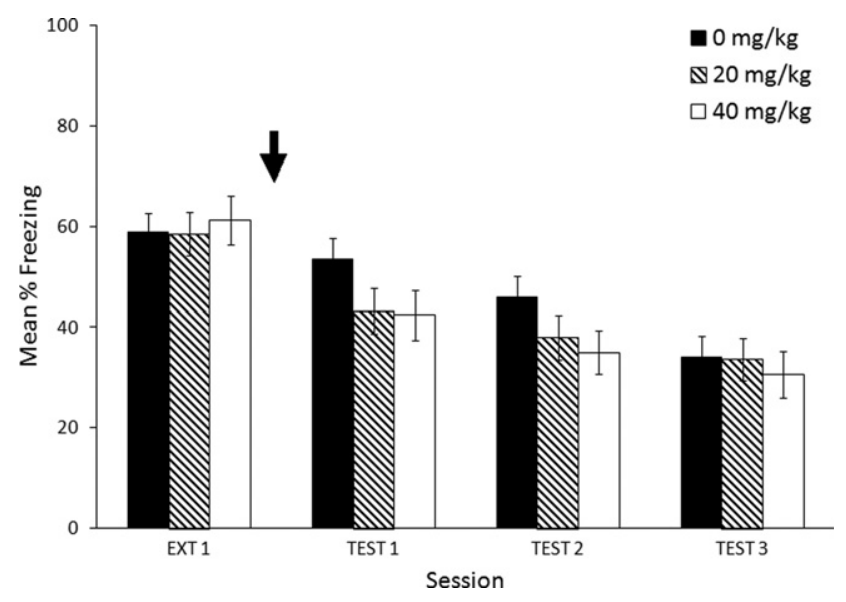

Figure 4. Effects of MPH (black arrow) administered $4 \mathrm{~h}$ after a 12-min extinction session. Mice that received methylphenidate $(0,20$, and $40 \mathrm{mg} / \mathrm{kg}) 4 \mathrm{~h}$ following extinction did not show significant differences in freezing response during test days. Error bars indicate SEM. 


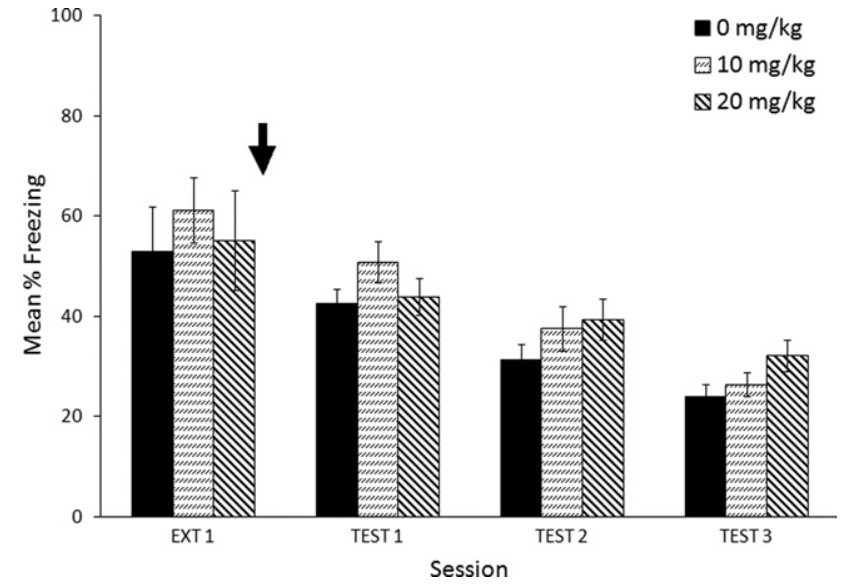

Figure 5. Effects of MPH (black arrow) administered immediately after a 3 -min extinction session. Mice that received methylphenidate $(0,10$, and $20 \mathrm{mg} / \mathrm{kg}$ ) following brief (3-min) extinction did not show significant differences in freezing response during test days. Error bars indicate SEM.

contribution of locomotor effects from effects on learning. Another challenge is that the interoceptive state induced by these drugs may impair attention, which would create a non-specific deficit in extinction learning. Administering $\mathrm{MPH}(10 \mathrm{mg} / \mathrm{kg})$ immediately preceding an extinction session (Experiment 1) enhanced extinction on the following day, but the effects of $\mathrm{MPH}(10 \mathrm{mg} / \mathrm{kg})$ on locomotor performance during the extinction session complicate interpretation of the long-term effects. It is possible, for example, that the animal may superstitiously learn that increased locomotor activity prevents the occurrence of shock and would engage this behavior upon return to the context (Skinner 1948). Thus, there are several interpretational challenges associated with pre-session administration of MPH.

By administering MPH immediately after extinction, we avoided some of the issues associated with pre-session injections. This approach ensures that all groups experience extinction under common conditions, and this treatment resulted in differences during test days after extinction. The persistence of the attenuation of freezing after a single injection is particularly notable, because MPH is generally prescribed as a chronic treatment. The changes in fear behavior here cannot be attributed to alterations in the acquisition of extinction or interference of fear memory retrieval and are most likely related to the effects of MPH on consolidation of extinction. It is unlikely that the effect is simply due to locomotor activation (Supplemental Fig. 2), and previous research has demonstrated that MPH's locomotor-activating effects do not persist to days when the drug is absent (Gaytan et al. 1997). The extinction enhancement effect did not occur when injections followed extinction by $4 \mathrm{~h}$ (Experiment 3) or when extinction sessions were short (Experiment 4). The absence of an effect with brief extinction trials may suggest that some withinsession extinction is required for MPH to have enhancing effects (Weber et al. 2007). Future experiments could clarify these effects by using targeted microinjections of MPH into the prefrontal cortex (PFC), amygdala, or hippocampus, because these are regions that may differentially mediate aspects of fear retrieval and extinction (Maren and Quirk 2004; Busti et al. 2011).

Many studies that have examined MPH have been interested in the drug's effects on attention while MPH is active within the animal (Arnsten and Dudley 2005; Berridge et al. 2006; Tye et al. 2010). Most of these studies have used rat models rather than mice, which show different pharmacokinetic properties with MPH (Faraj et al. 1974), such as longer times for drug metabolism in rats compared with mice. Comparisons between mouse dosing and human dosing are difficult to quantify due to the differences in affinity that are shown by mouse DAT and human DAT to MPH, with MPH inhibiting human DAT fourfold more potently than mouse DAT (Wu and Gu 1999). Mouse NET and human NET show similar affinities to MPH (Han and Gu 2006). In attention or learning tasks with drug present, a locomotor effect from $\mathrm{MPH}$ would be detrimental to measuring behavior. However, in the context of enhancing extinction consolidation in mice, it is possible that higher doses of MPH may be necessary to create sufficiently large signaling changes from baseline levels for detectable differences in learning. Future studies could test human subjects undergoing exposure therapy while receiving MPH at clinically prescribed doses ranging up to $1.5 \mathrm{mg} / \mathrm{kg}$ (Arnsten and Dudley 2005), which may provide comparable extinction enhancements in humans. Although the dosing is quite different between mice and humans, the mechanism of action for extinction enhancements is likely to be closely related.

Activation of the prefrontal cortex by methylphenidate (Berridge et al. 2006) is one candidate for the mediation of the extinction enhancements reported in this study. The infralimbic region of the prefrontal cortex is thought to modulate consolidation and expression of fear extinction (Vidal-Gonzalez et al. 2006; Burgos-Robles et al. 2007), and Marsteller et al. (2002) demonstrated that when MPH is paired with a mild stressor, there is a large increase in dopamine release in the medial prefrontal cortex compared with MPH administered with no stressor or $2 \mathrm{~h}$ following a stressor. Arnsten and Dudley (2005) demonstrated that MPH actions are mediated in part by D1 receptors, and Hikind and Maroun (2008) showed that blockade of infralimbic cortex D1 receptors impairs consolidation of extinction. The interaction between stress-induced norepinephrine release and methylphenidate is less clear (Marsteller et al. 2002), although previous studies in our laboratory have shown the importance of adrenergic receptors to fear and drug memory consolidation following extinction (Bernardi et al. 2009; Bernardi and Lattal 2010). These previous studies, in combination with our present study, suggest that methylphenidate is likely to be specifically involved with enhancing consolidation of an extinction memory through dopaminergic and noradrenergic mechanisms when administered immediately following extinction.

An alternative explanation for the effects seen with postextinction methylphenidate may be related to counterconditioning of the fearful context. Using an aversive-to-appetitive transfer procedure, Bouton and Peck (1992) showed that cues previously associated with an aversive outcome can be trained to predict a rewarding outcome. Bouton (1993) proposed that the counterconditioning effect was not due to incompatible behavioral responses, but rather a central interaction between a rewarding memory and an aversive memory. Methylphenidate is known to induce conditioned place preference (CPP) (Nolley and Kelley $2007)$ at the dose range $(20 \mathrm{mg} / \mathrm{kg})$ that was effective for enhancing extinction in this study, indicating that an interaction between reward networks and the fear extinction circuit may allow for extinction enhancement. Because fear and drug extinction circuitry overlap in the prefrontal cortex (Peters et al. 2009), MPH's rewarding properties and unique pharmacology (Volkow et al. 1995; Berridge et al. 2006) could be quite useful for behavioral therapies involving extinction learning.

In these experiments, it appears that dopamine and norepinephrine transporter blockade following an extinction session caused enhanced consolidation. These findings have implications for disorders such as ADHD and PTSD. As discussed by Johansen et al. (2002), ADHD is associated with dysfunctional dopaminergic signaling, along with failures in reinforcement and extinction learning. Treatment with MPH may have several different beneficial 
effects on behavior, including restoration of extinction processes that are deficient in ADHD, and weakening of PTSD symptoms in veterans (Houlihan 2010). This study demonstrates that MPH treatment in combination with fear extinction will enhance extinction retention and suggests a possible pharmacological treatment that could be useful in combination with exposure therapy for patients with fear disorders.

\section{Materials and Methods}

\section{Subjects}

Male C57BL/ 6 mice $(n=240)$ ranging from 7 to 11 wk of age $(28 \pm 5 \mathrm{~g})$ were used in these experiments. Animals were purchased from Jackson Laboratory (Bar Harbor, ME) and given at least $7 \mathrm{~d}$ in the vivarium prior to experimental use. For $2 \mathrm{~d}$ before conditioning, mice were handled and given a $0.2-\mathrm{mL}$ saline $(0.9 \%$ $\mathrm{NaCl}$ ) injection each day to habituate to injections and handling. Animals were housed four to a cage, and all animals within a cage received the same experimental conditions. Polycarbonate cages were held in a Thoren rack, and animals were given access to food and water ad libitum. Vivarium and experiment room temperatures were maintained at $22^{\circ} \mathrm{C} \pm 1{ }^{\circ} \mathrm{C}$, and subjects were maintained on a 12-h light-dark cycle (lights on $0600 \mathrm{~h}-1800 \mathrm{~h}$ ). Animals were moved from the vivarium to the experiment room $60 \mathrm{~min}$ before the start of an experiment, and experiments were conducted between 1100 and $1700 \mathrm{~h}$. All experimental procedures were approved by the OHSU Institutional Animal Use and Care Committee and were conducted in accordance with National Institutes of Health (NIH) "Principles of Laboratory Animal Care" (NIH Publication No. 86-23, revised 1985).

\section{Drugs}

Methylphenidate $\mathrm{HCl}$ (Sigma-Aldrich) was dissolved in saline $(0.9 \% \mathrm{NaCl})$ at concentrations of $2.5,5,10,20$, and $40 \mathrm{mg} / \mathrm{kg}$. Drug was administered intraperitoneally (i.p.) in a volume of $10 \mathrm{~mL} / \mathrm{kg}$. Doses were selected based on previous studies indicating MPH enhancement of cognitive function and fear memory (Arnsten and Dudley 2005; Nolley and Kelley 2007; Zheng et al. 2008).

\section{Apparatus}

\section{Fear conditioning}

Four Coulbourn Instruments mouse-conditioning chambers (H10-11M-TC) were used. Chambers were housed in sound and light-attenuating cabinets with a fan providing $70 \mathrm{~dB}$ of background noise. A Plexiglas cylinder, $21.5 \mathrm{~cm}$ in diameter and $23 \mathrm{~cm}$ in height, was placed on a grid floor in the chamber. The grid floor consisted of stainless steel rods, $3.2 \mathrm{~mm}$ in diameter, spaced $6.4 \mathrm{~mm}$ apart. Scrambled shock $(2 \mathrm{sec}, 0.35 \mathrm{~mA})$ was delivered to the grid floor by a computer controlled shock generator (Coulbourn H13-15). Above the Plexiglas cylinder, an automated infrared activity monitor (Coulbourn H24-61) recorded activity in Graphic State 3.01 software.

\section{Behavioral procedures}

\section{General conditioning procedure}

On Day 1 (Acquisition), subjects received a 12-min exposure to the context with four unsignaled shocks, delivered at 2.5, 5, 9, and $11.5 \mathrm{~min}$. In all experiments, groups were matched following acquisition to ensure equal terminal freezing levels across MPH dose assignments. On Day 2, mice received a 12-min (Experiments 1, 2, and 3) or a 3-min (Experiment 4) nonreinforced exposure to the context (Extinction). In all post-session injection experiments (Experiments 2, 3, and 4), groups were matched within experiments to ensure equal levels of terminal freezing before MPH injections. Animals with higher freezing response during the final 3 -min block compared with the initial 3-min block on Day 2 were excluded from data analysis due to their failure to extinguish fear responding in Experiments 2 and 3. On Days 3-5 (Test Days 1-3), animals received 12-min nonreinforced exposures to the context on each day.

\section{Experiment 1: Pre-extinction administration of MPH}

This experiment tested the effects of acute MPH given before an extinction session to determine whether MPH could enhance acquisition and retention of extinction. On Day 1 , animals $(n=$ 8 per group) received an injection of saline, followed by acquisition training. On Day 2, animals received either MPH $(2.5,5$, $10 \mathrm{mg} / \mathrm{kg}$ ) or saline, followed immediately by a 12-min extinction session (Fig. 1). On Days 3-5, animals received an injection of saline, followed by additional 12-min extinction sessions.

\section{Experiment 2: Post-extinction administration of MPH}

This experiment examined the effect of acute MPH administered immediately after an extinction session. The post-session administration allowed animals to be given drug or saline under common conditions during a period of memory consolidation (Abel and Lattal 2001). On all days of conditioning and testing, animals received injections post-session. On Day 1 , animals received an acquisition session with administration of saline. On Day 2, animals received either MPH or saline immediately following extinction. On Days 3, 4, and 5, animals received injections of saline following 12-min nonreinforced sessions (Fig. 2). The doses of $\mathrm{MPH}$ that were given to the animals following extinction were distributed across three separate replications. Experiment 2 a consisted of doses $0,2.5,5$, and $10 \mathrm{mg} / \mathrm{kg}$ ( $n=8$ per group). Experiment $2 \mathrm{~b}$ consisted of doses 0,10 , and $20 \mathrm{mg} / \mathrm{kg}(n=16$ per group). Experiment $2 \mathrm{c}$ consisted of doses 0,20 , and $40 \mathrm{mg} / \mathrm{kg}$ ( $n=8$ per group). Doses that were replicated were pooled for final analysis following statistical confirmation that there was no effect of replication on any dose. Data for Test Days 1-3 for each dose compared with saline are shown in 3-min blocks in Figure 3. Six animals were removed from both the saline and $10 \mathrm{mg} / \mathrm{kg}$ groups, and four animals were removed from the $20 \mathrm{mg} / \mathrm{kg}$ group because they failed to meet extinction criterion.

Experiment 3: Four-hour delayed administration of MPH In this experiment, the end of the extinction session and the administration of MPH were separated by $4 \mathrm{~h}$. The temporal separation tested whether drug administration, unpaired from extinction training, would affect freezing response on the following days (Burgos-Robles et al. 2007). The animals ( $n=12$ per group) still received saline injections on all days following exposure to the context in order to ensure equivalence to treatment conditions in Experiment 2. However, in this experiment, following the extinction session, all animals received an injection of saline and $4 \mathrm{~h}$ later received either MPH (20 or $40 \mathrm{mg} / \mathrm{kg}$ ) or saline (Fig. 4). In accordance with exclusion criteria, one animal was removed from both saline and $40 \mathrm{mg} / \mathrm{kg} \mathrm{MPH}$ groups, and two animals were removed from the $20 \mathrm{mg} / \mathrm{kg}$ MPH group for final analysis.

\section{Experiment 4: Brief extinction followed by administration of MPH}

This experiment tested whether MPH can facilitate extinction under conditions of reduced within-session extinction. A brief extinction period should ensure that animals only undergo partial extinction and may increase the detection of MPH enhancements. Animals ( $n=8$ per group) received injections of saline on Days $1,3,4,5$, and 26. On Day 2, animals received either MPH (10, $20 \mathrm{mg} / \mathrm{kg}$ ) or saline following a brief (3-min) extinction period (Fig. 5).

\section{Data analysis}

Fear memory expression was determined by freezing response within the context. Freezing was defined as an episode of at least 
$3 \mathrm{sec}$ of inactivity. Total freezing time was divided by $12 \mathrm{~min}$ to calculate percentage of time freezing in each day. Data analyses were performed with SPSS version 17.0. Data for Acquisition, Extinction, and Brief Extinction were analyzed using analysis of variance (ANOVA). Test Days 1-3 were analyzed using Repeated Measures ANOVA with Day as a within-subjects factor and Dose as a between-subjects factor. When sphericity could not be assumed for data, reported degrees of freedom reflect a Greenhouse-Geisser estimate. All post hoc comparisons of Repeated Measures ANOVA data were performed using a Dunnett's test. Two-tailed $t$-tests were used for post hoc analysis of 3-min blocks for each post-session dose compared with saline. Equal variance was assumed based on nonsignificant Levene's tests for each dose at reported time points. For all statistical tests, the $\alpha$ was set to 0.05 .

\section{Acknowledgments}

This research was supported by grants from the NIH (NIDA T32DA007262, NIDA R01DA025922, NIMH R01MH077111).

\section{References}

Abel T, Lattal KM. 2001. Molecular mechanisms of memory acquisition, consolidation and retrieval. Curr Opin Neurobiol 11: 180-187.

Arnsten AFT, Dudley A. 2005. Methylphenidate improves prefrontal cortical cognitive function through $\alpha-2$ adrenoceptor and dopamine D1 receptor actions: Relevance to therapeutic effects in Attention Deficit Hyperactivity Disorder. Behav Brain Funct 1: 2-11.

Bernardi RE, Lattal KM. 2010. A role for $\alpha$-adrenergic receptors in extinction of conditioned fear and cocaine conditioned place preference. Behav Neurosci 124: 204-210.

Bernardi RE, Ryabinin AE, Berger SP, Lattal KM. 2009. Post-retrieval disruption of a cocaine conditioned place preference by systemic and intrabasolateral amygdala $\beta 2$ - and $\alpha 1$-adrenergic antagonists. Learn Mem 16: 777-789.

Berridge CW, Devilbiss DM, Andrzejewski ME, Arnsten AFT, Kelley AE, Schmeichel B, Hamilton C, Spencer RC. 2006. Methylphenidate preferentially increases catecholamine neurotransmission within the prefrontal cortex at low doses that enhance cognitive function. Biol Psychiatry 60: 1111-1120.

Borowski TB, Kokkinidis L. 1998. The effects of cocaine, amphetamine, and the dopamine D1 receptor agonist SKF 38393 on fear extinction as measured with potentiated startle: Implications for psychomotor stimulant psychosis. Behav Neurosci 112: 952-965.

Bouton ME. 1993. Context, time and memory retrieval in the interference paradigms of Pavlovian learning. Psychol Bull 114: 80-99.

Bouton ME, Peck CA. 1992. Spontaneous recovery in cross-motivational transfer (counterconditioning). Anim Learn Behav 20: 313-321.

Burgos-Robles A, Vidal-Gonzalez I, Santini E, Quirk GJ. 2007. Consolidation of fear extinction requires NMDA receptor-dependent bursting in the ventromedial prefrontal cortex. Neuron 53: 871-880.

Busti D, Geracitano R, Whittle N, Dalezios Y, Mańko M, Kaufmann W, Sätzler K, Singewald N, Capogna M, Ferraguti F. 2011. Different fear states engage distinct networks within the intercalated cell clusters of the amygdala. J Neurosci 31: 5131-5144.

Carmack SA, Wood SC, Anagnostaras SG. 2010. Amphetamine and extinction of cued fear. Neurosci Lett 468: 18-22.

Faraj BA, Israili ZH, Perel JM, Jenkins ML, Holtzman SG, Cucinell SA, Dayton PG. 1974. Metabolism and disposition of methylphenidate- ${ }^{14} \mathrm{C}$ : Studies in man and animals. J Pharmacol Exp Ther 191: $535-547$.

Gaytan O, al-Rahim S, Swann A, Dafny N. 1997. Sensitization to locomotor effects of methylphenidate in the rat. Life Sci 61: 101-107.

Han DD, Gu HH. 2006. Comparison of the monoamine transporters from human and mouse in their sensitivities to psychostimulant drugs. BMC Pharmacol 6: 6. doi: 10.1186/1471-2210-6-6.

Hikind N, Maroun M. 2008. Microinfusion of the D1 receptor antagonist, SCH23390 into the IL but not the BLA impairs consolidation of extinction of auditory fear conditioning. Neurobiol Learn Mem 90: 217-222.

Holtzmann-Assif O, Laurent V, Westbrook RF. 2010. Blockade of dopamine activity in the nucleus accumbens impairs learning extinction of conditioned fear. Learn Mem 17: 71-75.

Houlihan DJ. 2010. Psychostimulant treatment of combat-related posttraumatic stress disorder. J Psychopharmacol 25: 1568-1572.

Johansen EB, Aase H, Meyer A, Sagvolden T. 2002. Attention-deficit/ hyperactivity disorder behaviour explained by dysfunctioning reinforcement and extinction processes. Behav Brain Res 130: 37-45.

Maren S, Quirk GJ. 2004. Neuronal signaling of fear memory. Nat Rev Neurosci 5: 844-852.

Marsteller DA, Gerasimov MR, Schiffer WK, Geiger JM, Barnett CR, Schaich Borg J, Scott S, Ceccarelli J, Volkow ND, Molina PE, et al. 2002. Acute handling stress modulates methylphenidate-induced catecholamine overflow in the medial prefrontal cortex. Neuropsychopharmacology 27: $163-170$.

Mazei MS, Pluto CP, Kirkbride B, Pehek EA. 2002. Effects of catecholamine uptake blockers in the caudate putamen and subregions of the medial prefrontal cortex of the rat. Brain Res 936: 58-67.

Miczek KA, Luttinger D. 1978. Differential attenuation of two kinds of conditioned suppression by d-amphetamine and pentobarbital. J Pharmacol Exp Ther 205: 282-290.

Mueller D, Olivera-Figueroa LA, Pine DS, Quirk GJ. 2009. The effects of yohimbine and amphetamine on fear expression and extinction in rats. Psychopharmacology 204: 599-606.

Myers KM, Davis M. 2007. Mechanisms of fear extinction. Mol Psychiatry 12: $120-150$.

National Institutes of Health. 1985. NIH Publication 86-23 Revised. In Guide for the care and use of laboratory animals. Public Health Service, National Institutes of Health.

Nolley EP, Kelley BM. 2007. Adolescent reward system perseveration due to nicotine: Studies with methylphenidate. Neurotoxicol Teratol 29: $47-56$.

Peters J, Kalivas PW, Quirk GJ. 2009. Extinction circuits for fear and addiction overlap in the prefrontal cortex. Learn Mem 16: 279-288.

Pezze MA, Feldon J. 2004. Mesolimbic dopaminergic pathways in fear conditioning. Prog Neurobiol 74: 301-320.

Pezze MA, Bast T, Feldon J. 2003. Significance of dopamine transmission in the rat medial prefrontal cortex for conditioned fear. Cereb Cortex 13: $371-380$.

Quirk GJ, Mueller D. 2008. Neural mechanisms of extinction learning and retrieval. Neuropsychopharmacology 33: $56-72$.

Quirk GJ, Garcia R, Gonzalez-Lima F. 2006. Prefrontal mechanisms in extinction of conditioned fear. Biol Psychiatry 60: 337-343.

Shin LM, Rauch SL, Pitman RK. 2006. Amygdala, medial prefrontal cortex, and hippocampal function in PTSD. Ann N Y Acad Sci 1071: 67-79.

Skinner BF. 1948. Superstition in the pigeon. J Exp Psychol 38: 168-172.

Sorg BA, Kalivas PW. 1993. Effects of cocaine and footshock stress on extracellular dopamine levels in the medial prefrontal cortex. Neuroscience 53: 695-703.

Tye KM, Tye LD, Cone JJ, Hekkelman EF, Janak PH, Bonci A. 2010. Methylphenidate facilitates learning-induced amygdala plasticity. Nature 13: 475-481.

Vidal-Gonzalez I, Vidal-Gonzalez B, Rauch SL, Quirk GJ. 2006. Microstimulation reveals opposing influences of prelimbic and infralimbic cortex on the expression of conditioned fear. Learn Mem 13: $728-733$

Volkow ND, Ding YS, Fowler JS, Wang GJ, Logan J, Gatley JS, Dewey S, Ashby C, Liebermann J, Hitzemann R, et al. 1995. Is methylphenidate like cocaine? Studies on their pharmacokinetics and distribution in the human brain. Arch Gen Psychiatry 52: 456-463.

Weber M, Hart J, Richardson R. 2007. Effects of D-cycloserine on extinction of learned fear to an olfactory cue. Neurobiol Learn Mem 87: 476-482.

$\mathrm{Wu}$ X, Gu H. 1999. Molecular cloning of the mouse dopamine transporter and pharmacological comparison with the human homologue. Gene 233: $163-170$.

Zheng XL, Liu F, Wu XW, Li BM. 2008. Infusion of methylphenidate into the basolateral nucleus of amygdala or anterior cingulate enhances fear memory consolidation in rats. Sci China C Life Sci 51: 808-813.

Received November 2, 2011; accepted in revised form December 5, 2011. 


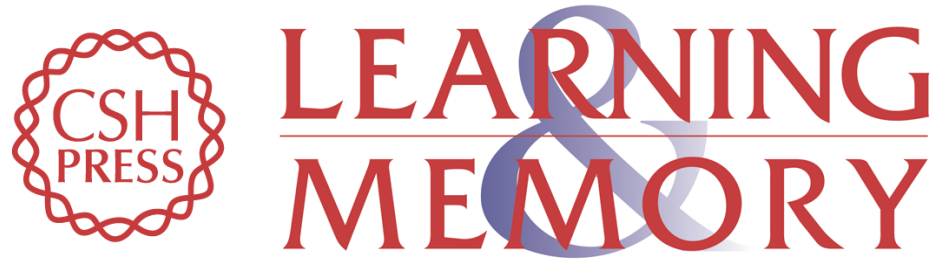

\section{Methylphenidate enhances extinction of contextual fear}

Antony D. Abraham, Christopher L. Cunningham and K. Matthew Lattal

Learn. Mem. 2012, 19:

Access the most recent version at doi:10.1101//m.024752.111

Supplemental http://learnmem.cshlp.org/content/suppl/2012/01/17/19.2.67.DC1

Material

References This article cites 39 articles, 7 of which can be accessed free at: http://learnmem.cshlp.org/content/19/2/67.full.html\#ref-list-1

License

Email Alerting Receive free email alerts when new articles cite this article - sign up in the box at the Service top right corner of the article or click here. 